\title{
DO SAGRADO AO PROFANO: A Urbes em Ragtime
}

\author{
Wilton Fred C. de Oliveira \\ Profo ${ }^{\circ}$ do CEFET-PR, unidade de Curitiba. Doutorando em Teoria da Literatura pela UFSC
}

RESUMO: O presente ensaio, baseado no romance Ragtime, de E. L. Doctorow, é uma análise da cidade na alta modernidade, de suas contradicões, desumanização e dessacralização, tendo como contraponto a Urbes grecoromana, espaço este produzido para o povo. Procura-se mostrar nesse percurso a exteriorização da cidade, que de local para o homem, transformou-se em local no qual a liberdade humana foi sacrificada, face à profanação do sagrado: família, tradição, produção; resultado da nova ordem econômica implantada pela modernidade.

PALAVRAS-CHAVES: Urbes, cidade, Ragtime, sagrado, profano.

Sit tibi terra levis

Metam. X, 62, Ovídio

Era costume na Grécia e Roma antiga, ao enterrarem seus mortos, no final da cerimônia fúnebre, chamarpor três vezes a alma do morto pelo nome que este havia usado em vida. Faziam-lhe votos de vida feliz debaixo da terra. Dizia-se a ele por três vezes: Passa bem. E acrescentava-se: Que a terra Ihe seja leve![i] Os mortos eram considerados, afirma-nos Fustel de Coulanges, deuses subterrâneos. Segundo este historiador

em Ésquilo, o filho invoca seu falecido pai por estas palavras: "Oh tu que és um deus sob a terra". Eurípides, falando de Alceste acrescenta: junto do teu túmulo o viandante parará e dirá: "' Aqui vive agora a divindade bem-aventura". Os romanos davam aos mortos o nome de manes. "Prestai aos deuses manes quanto Ihes é devido, Diz Cícero, são homens que abandonaram esta vida terrena; considerai-os como seres divinos".[ii]

Com a veneração dos antepassados, dos ancestrais e conseqüentemente o depósito de seus restos mortais na terra, muitas vezes seguido de bens e animais, seja de estimação ou pertencentes à riqueza, a terra era vista como um ente sagrado, depositária dos deuses. Sagrada era a terra; sacra, a casa. Toda habitação grega ou romana possuía um altar, no qual havia sempre restos de cinza e brasas, cabendo ao dono manter a chama acesa. Desgraçada a 
casa cujo fogo se extinguisse. O fogo era a providência da família, o deus presente. Tudo era sagrado para o homem antigo. Desde o levantar, o alimentar-se, o deitar-se era um ato divino. $O$ mundo estava povoado de deuses.

Assim como a terra, a casa e os mortos eram sagrados, também era a família. Entre os vivos e os mortos havia pouquíssima distância. Somente alguns passos, tantos quantos os separam a casa do túmulo. Consoante Coulanges, a antiga família "era assim um grupo de pessoas a quem a religião permitia invocar o mesmo lar e oferecer a refeição fúnebre aos mesmos antepassados"[iii]. Não existia separação entre sagrado e profano. Mundo centrado nos mortos, na casa, no pai. Nesse mundo somente digladiavam os deuses e os demônios. A cidade ainda não tinha ingerência sobre a família, esta era centrada na figura paterna, a qual tinha plena autoridade sobre os membros e seus agregados. Certamente que se a cidade tivesse sido anterior à voz familiar aquela teria se apropriado da casa, dos filhos, da mulher, do patriarca e retirado desta figura o direito de legislar sobre os seus membros.

Com o passar do tempo, as associações familiares e fratrias começaram a se alargar, formando-se as tribos e posteriormente as cidades. Temos, portanto, como raízes das cidades, a seqüência: família, fratria, tribo e cidades. Mas para que forças tão fechadas pudessem se abrir umas às outras era necessário que um valor maior suplantasse os deuses endógenos. Em primeiro lugar foram os ataques exógenos que enfraqueceram os grupos familiares e a dificuldade de encontrar víveres. Somando-se a esses fatores houve algo que suplantou todas as forças externas: a crença. Nada mais poderoso existe sobre a alma do que ela. Somente ela é capaz de unificar povos contraditórios ou dispersar povos irmãos. É essa força, segundo Coulanges,

\footnotetext{
obra do nosso espírito, mas encontramos nesta liberdade para modificá-la a seu gosto. A crença é de nossa criação, mas a ignoramos. É humana, e a julgamos sobrenatural. É efeito do nosso poder, e é mais forte do que nós. Está em nós, não nos deixa, e cada momento nos fala. Se nos manda obedecer, obedecemos; se nos indica deveres, submetemo-nos. O homem pode dominar a natureza, mas está sempre sujeito ao seu próprio pensamento.[iv]
}

Foram essas crenças, capazes de impelir o homem a obedecer, que tiveram papel fundamental na formação das urbes e posteriormente das cidades. Enraizaram os povos, unificando-os em torno do mesmo ideal: ora em torno de um totem, ora em torno de um deus, ora em torno de um sacerdote, chefe e outras autoridades ou fetiches. A urbes surgiu como um santuário, local de reunião, quando as famílias, as fratrias e as tribos convencionaram unir-se e terem o mesmo culto comum. Segundo Coulanges, a fundação da urbe, sempre foi um culto religioso, sempre tendo uma conotação de axis múndi, ou um retorno in illo tempore.

Quando o homem saía de sua urbes, era costume levar consigo um punhado do solo e dos restos de seus antepassados. Toda nova construção e toda inauguração de uma nova morada equivalia para o homem antigo a um novo começo, a uma nova vida. Todo começo 
repetia o começo primordial, quando o Universo viu pela primeira vez a luz do dia. Quando Deus disse Fiat Lux. Era preciso cumprir esse ritual para que o novo lugar adotado pudesse continuar sendo a terra dos ancestrais. O punhado de terra, considerado o centro do mundo, no qual foram enterrados os antepassados, era espargido sobre a nova terra, em torno da urbes recém fundada, santificando-a. Julgava o novo fundador haver trazido para a nova possessão as almas de seus antepassados. Estas, ali reunidas, seriam objeto de culto perpétuo e velariam pelos seus descendentes. As urbes tinham um caráter sagrado e conseqüentemente eram criadas para serem eternas.

Com o passar do tempo, o aumento populacional, a necessidade de sobrevivência profanarão a terra a qual fundir-se-á em espaço público e privado. Na Grécia antiga, veremos surgir a ágora, local de reunião pública, também, posteriormente, transformada em mercado. Num primeiro momento, tomando por base a cidade grega, afirma-nos Lewis Mumford que rompido o sagrado "o que unifica a cidade é o interesse comum pela justiça e a finalidade comum, de procurar a boa vida"[v]. A cidade do princípio helênico era uma comunidade decidida, para seu próprio bem, a continuar pequena. Mas forças externas e internas fizeram com que as cidades se expandissem. Antes de ser aquele ambiente sagrado, agora abrigavam em si mercados, portos, interesses comerciais e conseqüentemente uma população profana: marinheiros, comerciantes, viajantes e outros. Somando-se a isso o eixo da casa começou a deslocar-se para a cidade: as decisões que eram familiares, tribais adquiriram um âmbito de decisão maior, a ágora. Surgiram praças, ruas, edifícios públicos, poderes externos e temporais que passaram a interferir na decisão da família. O profano invadiu o sagrado, e a cidade deixou

de ser o palco de um drama significativo, no qual cada um teria um papel, com falas a dizer: tornouse, pelo contrário, um pomposo mostruário de poder: e suas ruas, apropriadamente, apresentavam apenas fachadas bidimensionais, que serviam de máscara para um generalizado sistema de arregimentação e exploração.[vi]

Essa foi a herança que os novos tempos receberam. Cresceu o contingente populacional, e os séculos posteriores não conseguiram reverter o quadro de desumanização e de deslocamento do poder. A própria Idade Média recebeu uma estrutura citadina fixa, acirrando, nesse período até desembocar no Renascimento a expansão do comércio, a desumanização do meio ambiente, a alteração na produção e nas relações humanas. A lgreja substituiu a antiga urbes, e o resto do mundo transformou-se numa possessão do homem, reino das máquinas, das navegações, da exploração da força produtiva.

Cita-nos Munford que entre os séculos XV e XVIII, 
principalmente a do despotismo ou da oligarquia centralizada, habitualmente personificada num Estado nacional.[vii].

A cidade, com o advento do Estado nacional, cresceu e seus habitantes foram imergindo no anonimato. As estruturas de poder aumentaram, deslocando as ações individuais para os dispositivos técnicos, transformando uma massa de homens participantes e atuantes em uma sociedade disciplinar, composta por sujeitos assujeitados, solitários e anônimos, habitantes de um espaço impossível de se ver o conjunto. Os homens se perderam, minimalizam-se diante das imensas construções: estradas, prédios, máquinas, vivendo numa posição inferior em relação aos próprios objetos que constroem. Passaram a habitar imersos,

embaixo, a partir dos limiares onde cessa a visibilidade, vivem os praticantes ordinários da cidade. Forma elementar dessa experiência, eles são caminhantes, pedestres, Wandersmänter, cujo corpo obedece aos cheios e vazios de um "texto" que escrevem sem poder lê-lo. Esses praticantes jogam com espaços que não se vêem; têm dele um conhecimento tão cego como no corpo-a-corpo amoroso.[viii]

Mumford mostra ao leitor de seu texto que no decorrer da história a exteriorização da cidade cresceu sacrificando a liberdade humana; enquanto Georg Simmel, em seu ensaio As grandes cidades e a vida do espírito[ix], revela o quanto as grandes metrópoles intensificaram a vida de seus habitantes impondo-Ihes impressões ininterruptas com sua evolução, moldandoIhes a consciência e a forma de se relacionar com os outros, com os objetos e com a própria espacialidade. O homem dessas novas metrópoles viu-se constantemente ameaçado em sua subjetividade, tornando-se impossível lutar contra as forças esmagadoras da sociedade destruidoras da sua autonomia e da existência. Se o homem primitivo teve que lutar contra as forças físicas, as intempéries, contra uma natureza não domada; hoje o homem moderno vive diante de um inimigo poderoso e invisível: o capitalismo, seus instrumentos de sedução, a ideologização, o assujeitamento, a desrazão do cotidiano e a impotência causada por esse grande Leviatã: as forças da Modernidade.

Karl Marx, em a Cidade como Degradação, já antecipa essa opressão e impotência do sujeito. Para esse pensador, o homem da caverna, apesar do mundo hostil em que vivia, sentiase mais abrigado que o pobre da cidade.

Retratando a situação do habitante do início do século XX, lamenta o pensador:

o covil onde o homem se aloja é alguma coisa de hostil, um "domicílio que contém em si uma potência estranha, que só se dá a ele na medida em que ele lhe dá seu suor" que ele não pode considerar como sua própria casa, - onde poderia finalmente dizer: aqui estou em casa, - onde sente mais estar na casa de um outro, na casa de um estranho que todo dia o espreita e o expulsa se não paga o aluguel. [X] 
Essa também é a condição subumana do homem citadino moderno que E. L. Doctorow colocará diante dos olhos do leitor em seu romance Ragtime. Descortinará para esse um indivíduo anônimo, assujeitado pelo sistema, perdido em grandes centros, frente a novas forças sociais avassaladoras, políticas e econômicas, que se foram sedimentando no decorrer de séculos de vida do homem sobre a terra. A cidade das máquinas, do cinema, das grandes vitrinas, do espetáculo, não mais feita para que o homem dela participe enquanto cidadão, mas enquanto objeto de produção e consumo; Mais Valia, diria Marx!É nessa relação objetiva que a consciência do homem, paradoxalmente, se forma e se perde. Consciência imersa, produzida por um cárcere do qual o indivíduo não pode fugir, destruindo-lhe a sua profundidade e moral. São essas forças avassaladoras, inescrupulosas, opressoras que rompem com a dimensão do sacro. Delas diz Marx:

Ao nascimento da mecanização e da indústria moderna (...) segiu-se um violento abalo, como uma avalanche. Em intensidade e extensão. Todos os limites da moral e da natureza, de idade e sexo, de dia e noite, foram rompidos. O capital celebrou suas orgias[xi].

São esses homens assujeitados que desfilam na obra de Doctorow, em plena época da produção industrial do final e início do Século XX. Tempo em que Charles Baudelaire circulava pelas ruas como um flâneur, olhos de Walter Benjamin.

A pintura efetuada por Doctorow em seu romance não difere da retratada por Baudelaire em Flores do Ma, do final do século XIX, início do século XX. Uma sociedade em transformação, acelerada pelas novas formas de trabalho, lutas sociais, greves e a presença do novo, do fantástico seduzindo os homens, fazendo com que os valores mais eternos, como a tradição, a família e toda a solidez existente se desmanchem no ar. .

Nova York não se diferirá muito da França das barricadas, com seus anarquistas e trapeiros. Cidade de múltiplas cores, formas e homens será tomada pelo sensacionalismo do jornal, do cinema, das revistas; do carro, da máquina e de toda tecnologia que promete um mundo dinâmico e maravilhoso para um homem cansado do trabalho braçal. Mas ao contrário da promessa da tecnologia como solução para os males do homem, isso não se concretiza. $A$ esperança iluminista não chega a se cumprir na alta Modernidade. Exemplo disso é o painel pintado por E.L. Doctorow em Ragtime. Cidade repleta de imigrantes vindo da Itália e do leste da Europa, os quais a enfeavam acarretando problemas sociais. As ruas onde esses imigrantes se instalavam lembravam-Ihes a pátria, e pela subumana condição como viviam em seus cortiços e pela má conduta, eram desprezados pelos nova-iorquinos. 
filhas. Matavam-se tranqüilamente uns aos outros. Entre os que mais os desprezavam, contavam-se os irlandeses de segunda geração, cujos pais haviam sido culpados dos mesmos crimes. Garotos irlandeses puxavam as barbas dos velhos judeus, atiravam-nos ao chão, e viravam os carrinhos dos vendedores italianos.[xii]

Muitas dessas ruas em que viviam esse povo eram pavimentadas pela própria população, outras existiam em total descaso. Ao lado dessas pequenas ruas habitavam famílias inteiras muitas vezes aglomeradas numa só peça, apesar do trabalho de todos os membros da família - como é o caso da família de Tateh-, vivendo subumanamente sem sanitários e em ruas que cheiravam a excrementos. Já ia alto o grito de defensores, tais como do jornalista Jacob Riis, sobre a necessidade de criar moradias para os pobres, contudo, tão sem eco quanto na atualidade. Em oposição a esse quadro sombrio, existiam as grandes avenidas, no centro da cidade, como a Madison e a Quinta Avenida, locais das muitas mansões, verdadeiros palácios, objetos de contemplação da classe deserdada. O grande espetáculo da engenharia, fruto da técnica e da artes modernas.

Além desse lado sombrio da cidade nova-iorquina do final deste século, havia também as lojas, as vitrinas - objetos do desejo -, os cinemas, espalhados por todo canto da cidade. Consoante Sigmund Freud, personagem de Ragtime, os cinemas eram locais ao menos silenciosos se comparados ao restante da cidade. Cita o texto que a coisa mais opressora para Freud no Novo Mundo era o ruído. "O terrível alarido de cavalos e carroças, os sons metálicos e agudos dos bondes, a buzina dos automóveis"[xiii]. Na seqüência o narrador ainda descreverá uma cena de uma cidade que sofre com a poluição sonora: "O assustador comboio passava rugindo pelas janelas dos cortiços onde se esperava que pessoas morassem. As janelas estremeciam, os próprios prédios estremeciam."[xiv]

Somando-se a todo esse estado de miséria, o narrador, através da indignação de Freud com relação à América, retrata as más condições de vida em que vivia o povo. Má alimentação, escassez de banheiros públicos e milhões de homens desempregados. Os que trabalhavam, como os negros nas fazendas de tabaco, eram expostos a uma jornada estafante de treze horas diárias, ganhando seis cents a hora, fosse homem, mulher ou criança. Já nas fábricas de enlatados e nas usinas, a situação não era melhor. Grande era o número de pessoas mutiladas: perdiam os dedos, imprensavam as mãos, esmagavam as pernas. A situação aqui encontrada por Freud, levou-o a concluir: "a América é um erro, um erro gigantesco". [xv]

A cada rua que se entra em Nova lorque esse erro parece ser mais claro. A Rua Hester, por exemplo, era um mercado fervilhante de mascates, que vendiam legumes, frutas, galinhas e pães, transportados em carrinhos alinhados junto às calçadas. Alguns apartamentos eram completamente insalubres. O quarto do personagem Tateh possuía uma janela que dava para um respiradouro. "Todo apartamento não seria maior que um armário embutido grande"[xvi], escuro, local ao qual os olhos tinham que se acomodar.

Os agrupamentos de homens e a formação de cidades, antes de se tornar um meio eficaz 
para o crescimento do homem, têm trazido de forma assustadora a destruição de seus próprios membros. No agrupamento ocorrido na metrópole de Nova lorque, o narrador de Ragtime registrou maiores situações de constrangimento humano do que de edificação da humanidade. Evoluiu a cidade, e com ela novos dramas passaram a ser encenados. Com o descentramento do poder, e aperfeiçoamento das técnicas de controle e de domínio sobre a natureza, nasceram também

contribuições sombrias da civilização urbana: a guerra, a escravidão, a exagerada especialização vocacional e, em muitos lugares, uma persistente orientação para a morte. Essas instituições e atividades, constituindo uma "simbiose negativa", têm acompanhado a cidade na maior parte da sua história e ainda hoje se conservam em forma acentuadamente brutal."[xvii]

acrescida na Modernidade pela mídia que começou a despontar como um elemento de fabricação da mente do indivíduo. As revistas, os jornais e o cinema passaram a constituir-se em elementos de formação de caráter, de conduta e de opinião dos habitantes das cidades. Em Ragtime, o narrador aponta essa manipulação, quando do sensacionalismo criado em torno do julgamento de Harry K. Thaw, personagem que havia matado Stanford White, amante de sua esposa Evelyn Nesbit. Em se tratando do jornal, aborda o narrador:

Alguns notaram que a foto de Evelyn na primeira página de um jornal fazia esgotar a edição e compreenderam que existia um processo de ampliação, pelo qual os acontecimentos fixavam determinados indivíduos na mente do público em proporção mais ampla que o natural. Esses eram os indivíduos que representavam uma característica humana desejável com exclusão de todas as outras. Os homens de negócios perguntavam se poderiam criar tais elementos, não a partir dos acidentes do noticiário, e sim da deliberada manipulação de seus próprios meios. Se conseguissem, mais pessoas pagariam para ver espetáculos.[xviii]

As grandes metrópoles deixam de ver o homem em sua individualidade, ou de ser para ele, transformando-o num objeto de manipulação. Nasce o conceito de massa. E a meta dos primórdios da pólis grega de desenvolver o homem em sua potencialidade, a visão qualitativa, no decorrer da história, foi substituída pela quantitativa. Quanto a essa mudança de rumos, afirma-nos Mumford que a produção quantitativa tornou-se o único imperativo. E à medida que esse deslocamento aumentava em volume e em ritmo, o homem mais e mais se afastava de quaisquer objetivos humanamente desejáveis.[xix] Muito difícil para o homem moderno retomar as suas forças em uma cidade que continuamente o tem abarcado, "infinitesimando-o" diante das grandes estruturas de aço, de vidro, e das instituições de poder.

Na cidade moderna, do início do século passado, consoante Ragtime, são presentes as estruturas infinitesimais do homem. Circulam por elas entre o antigo e o novo, cabriolés, carros e bondes, soltando suas faíscas elétricas. Homens de chapéu e mulheres passeiam no crepúsculo sob lâmpadas elétricas, e o bonde vai sumindo, dando uma impressão de abandono 
a quem fica e de que as coisas estão em movimento ao passageiro. Tateh, do bonde, "viu passar a aldeia de sua infância, algumas verstas para além do prado. Um campanário de igreja projetava-se sobre uma colina" $[\mathrm{xx}]$ e o mundo se tornara móvel. A Terra girava, confirmando a observação de Galileu Galilei, séculos depois. E os homens tornaram-se minúsculos, e seus valores lassos. O que importava era o progresso, capaz de provocar nos mais ufanistas e crédulos os manifestos futuristas:

Trilhos! Trilhos! Aos visionários que escreviam para as revistas populares parecia que o futuro se encontrava no extremo de linhas paralelas. Havia estradas de ferro estendendo-se a longa distâncias, ferrovias elétricas interurbanas, vias urbanas, elevados lançando suas linhas de aço sobre a terra, ziguezagueando como a contextura de uma infatigável civilização,[xxi]

não distante do grito de Marinetti em seu manifesto:

Nós cantaremos as grandes multidões agitadas pelo trabalho, pelo prazer ou pela sublevação; cantaremos as marés multicores e polifônicas das revoluções; cantaremos o vibrante fervor noturno dos arsenais e dos estaleiros incendiados por violentas luas elétricas (...) os piróscafos aventurosos que farejam o horizonte, as locomotivas de largo peito, que pateiam sobre os trilhos...[xxii]

Antes de ser esse paraíso ufanístico dos crédulos e das máquinas, esse período revelará uma cidade nova iorquina, onde as massas serão exploradas, violentadas, por toda essa tecnologia. Período de greves trabalhistas, de grupos de anarquistas, representados pela figura de Emma Goldmann e de seus especialistas em greves. Universo não diferente do abordado por Benjamin[xxiii] através das palavras de Marx, ao dizer que os conspiradores eram alquimistas da revolução. Não é possível afirmar que estamos diante dos mesmos alquimistas, mas quem sabe frente a Tweedledum e Tweedledee[Xxiv], em se tratando da luta contra opressão da classe proletariada. Doctorow não esquecerá esse senão da história trabalhista americana. $\mathrm{Na}$ greve ocorrida na cidade industrial de Lawrence, Massachusetts, na Companhia American Woolen Company surge a figura dos profissionais das greves. Esses, consoante o texto, “...sabiam organizar rapidamente uma greve, vieram de Nova lork para orientar tudo" [xxv]. Quando esses organizadores foram presos, não tardou a substituição. Chegou a Lawrence, de trem, Big Bill Haywood, o mais famoso de todos os líderes grevistas.

A cidade, que deveria ser o local de convívio, de troca de experiência entre os homens, transforma-se no início do século XX, num cenário de luta de homens contra homens e de máquinas contra homens. Cada vez mais o homem vê-se desenraizado, sem profundidade, esmaecido em seus valores; imergindo em um sistema do qual não consegue fugir, tampouco preservar a sua subjetividade. Não é sem razão que Simmel dirá que 
os problemas fundamentais da vida moderna provém de que o indivíduo deseja a qualquer preço, diante das forças esmagadoras da sociedade, da herança histórica, da civilização e das técnicas, preservar a autonomia e a originalidade de sua existência. [xxvi]

Grande é o preço de sua luta pela autonomia. Preço pago por Coalhouse Walker e sua namorada Sarah, personagens de Ragtime, ao buscar justiça para a ofensa social que as pessoas condutoras dos órgãos de poder Ihes haviam imposto. O poder citadino se transformou em anônimo, sendo impossível para aqueles que se vêem agredidos saber a quem se dirige (tinha razão Michel Foucault). O grande perseguidor do próprio homem deixou de ser as grandes instâncias para ser o elemento próximo, tão anônimo quanto ele. Quando Walker toma a justiça nas próprias mãos, é porque antes de tudo não havia mais canais, como a agora da Grécia antiga, onde as necessidades do homens pudessem ser postas e discutidas. Walker, homem ofendido, lutando pela sua individualidade, estava também diante de outros homens ofendidos e assujeitados, incapazes de compreender a agressão que lhe fora cometida. A cidade Nova-iorquina, antes de ser um local feito para o homem, para o desenvolvimento das potencialidades humanas, é o local de deterioração física e moral de sua gente, principalmente do proletariado. É como nos diz Françoise Choay, citando Taine a respeito de Marselha "Uma cidade assim, assemelha-se aos grandes negociantes"[xxvii].

O final do século XIX e início do século XX deram forma a uma nova cidade. Ela surge como um elemento exterior ao indivíduo, local em que não há mais a reflexão, espaço para o individual, ou para a Arte contemplativa. Tanto que o personagem Tateh ao engajar-se no comitê de lutas trabalhistas para pintar posters, faixas, ouviu a seguinte advertência de seu chefe: "Não queremos arte, disse o homem. Queremos algo que desperte a ira. Queremos manter a fogueira acesa."[xxviii]. Tempos futuristas! Marinetti... A cidade agora é essa fogueira, de lutas de espetáculo, da máquina, do bonde, das indústrias, das vitrinas. Na luta pelo discurso, ganhou o capital. Fala a imprensa, o cinema, os meios de produção e as instituições econômicas.

Quanto aos mortos. Os vivos parecem ter cumprido ao pé da letra a fala de Cristo "Deixai os mortos enterrarem os seus mortos" Se já não há mais espaço nem para os vivos; para aqueles resta o vão entre uma cidade e outra. Observa o leitor através dos olhos da menina, filha de Tateh, quando este procurava um lugar decente onde ela pudesse crescer sem ser violentada pela grande metrópole nova iorquina[xxix].

Quanto aos nomes, ao termo que especifica, que dá uma identidade, somente os têm aquelas pessoas que se transformam em fenômeno sociais, para o bem ou para o mal, tais como Freud, Morgan, Walker, Thaw. Aquele que não pode ser modelo ou espetáculo inominável. A cidade ideal somente a República Platônica. Mesmo assim, excludente como a pólis grega - excludente como a Nova lorque retratada em Ragtime. Aquela somente para homens livres; esta somente para brancos capazes de participar do grande espetáculo 
proporcionado pelo capitalismo e de gerar espetáculo. A história do Capitalismo e da cidade moderna é certamente a história de Houdini. Ninguém melhor para ilustrá-la. Não é por acaso que Doctorow utiliza-se desse personagem durante quase toda a narrativa. Umbilical, apegado à mãe, sensacionalista, temperamental, em busca do novo. Sem enraizamento, ou profundidade. Desumano. Capaz de ir ao leito de dor de um trabalhador acidentado, para perguntar qual a sensação que esse sentiu na hora em que foi lançado à distância quando da explosão de uma caldeira. O que importa não é o homem, mas a sensação, o prazer que se pode ter diante do mais cruel, mórbido, ou fugaz acontecimento. Arrisca a sua vida no alto de um prédio. Espetáculo de todos. Ecce Homo numa corda bamba, equilibrando-se entre o animal e o super-homem.

Sagrado, profano são termos esmaecidos de seus significados. E a cidade se estende para lá, para lá, para lá, da própria cidade. Não havendo mais muros, ou espaços sagrados. $E$ os homens nos bondes, nos trens, nos carros, vêem a terra girando, girando, diante de vagos e imprecisos quadros impressionistas. Novos centros surgindo, intercalados por terrenos baldios e cemitérios - única realidade do homem, túmulos desprovidos de magia, do sagrado. Não há mais a terra dos ancestrais: Sit tibi terra Levis.

\section{BIBLIOGRAFIA:}

BENJAMIN, Walter, Charles Baudelaire um lírico no auge do capitalismo; trad. José Martins Barbosa, Hemerson Alves Baptista. - $1^{\text {a }}$. ed. - São Paulo : Brasiliense, 1989.

BERMAN, Marshall. - Tudo que é sólido desmancha no ar : a aventura da modernidade;

Trad. Carlos Felipe Moisés, Ana Maria L. Ioriatti. São Paulo: Companhia das Letras, 1986.

CARROLL, Lewis, - Aventuras de Alice; Trad. Sebastião Uchoa Leite. - $3^{a}$. edição - São Paulo : Summus, 1980

CHOAY, Françoise; O Urbanismo; - Trad. Dafne Nascimento Rodrigues. - São Paulo : Perspectiva, 2000.

COULANGES, Fustel, - A cidade Antiga. - Fustel de Coulanges, Numa Denis: trad. Fernando de Aguiar. - São Paulo : Martins Fontes, 1981.

DOCTOROW, E. L. - Ragtime; Trad. A. Weissenberg.- , Rio de Janeiro - RJ: Editora Record/Altaya, 1996.

ELIADE, Mircea, O Sagrado e o Profano: A Essência das Religiões; Trad. Rogério Fernandes. - Lisboa : Ed. Livros do Brasil Lisboa.

MARINETTI, F. T. - Fundação e Manifesto do Futurismo; IN: O Futurismo Italiano, Org. 
Aurora Fornoni Bernardini, - São Paulo : Perspectiva, 1980.

MUMFORD, Lewis, - A cidade na história : suas origens, transformações e perspectivas;

Trad. Neil R., da Silva. -4a . ed. - São Paulo : Martins Fontes, 1998.

[i] Coulanges, Fustel de, A Cidade Antiga, p. 16

[ii][ii] Idem, p. 23

[iii] Coulanges, p. 45

[iv] Coulanges, p. 137

[v] Mumford, Lewis, A Cidade na História:a, suas origens, transformações e perspectivas, p. 205 [vi] Mumford, p. 217

[vii] Idem, p. 376

[viii] Certeau, Michel de, As invenções do cotidiano, p. 171

[ix] Simmel, Georg, As grandes cidades e a vida do espírito, p. 330, IN: Choay, Françoise, $O$ Urbanismo.

[x] Marx, Karl. A Cidade como Degradação, p. 148, idem

[xi] Marx, Karl. O Capital, vol 1, IN: Marshall Berman, Tudo que é sólido desmancha no ar, p. 85

[xii] Doctorow E.L., Ragtime, p. 19

[xiii] Doctorow, E. L. p. 35

[xiv] Idem, p. 35

[xv] Idem, 37

[xvi] Idem, 43

[xvii] Mumford, Lewis, p. 613

[xviii] Doctorow, E.L., p. 69

[xix] Apud. Mumford, Lewis. p. 615

$[x x]$ Doctorow, E.L., p. 76

[xxi] Idem, p. 79

[xxii] Marinetti, F.T., Fundação e Manifesto do Futurismo, p. 34. IN: O futurismo Italiano, org. Aurora Fornoni Bernardi. 
[xxiii] Apud. Benjamin, Walter, Paris no Segundo Império, p. 15

[xxiv] Carroll, Lewis, Aventura de Alice no País das Maravilhas, p. 169

[xxv] Doctorow, p. 99

[xxvi] Simmel, Georg. As grandes cidades e a vida do espírito, p. 330, IN: Choay, Françoise, O Urbanismo.

[xxvii] Choay, Françoise. O urbanismo em questão, p. 4

[xxviii] Doctorow, p. 100

[xxix] Vide cap. 12. E.L. Doctorow, pp. 74-75. (E que destino haviam levado Tateh e sua filhinha? (...)Caminhando até a esquina, entraram no bonde no 12 que conduzia à Union Square. Ali transferiram-se para o número 8. (...) A lua despontou, a temperatura caiu e o bonde deslizou pela ampla avenida, com paradas ocasionais. Passaram por terrenos cobertos de relva intercalando-se com quarteirões de casas gêmeas, ainda em construção. Finalmente as luzes desapareceram e a meninazinha percebeu que viajavam nos limites de um grande cemitério, no alto de uma colina. As lousas e mausoléus erguiam-se contra o frio céu noturno lembrando-lhe $o$ destino de sua mãe. (...) A essa altura de nossa história existia um sistema bem desenvolvido de linhas de bondes interurbanos. (...) Pela manhã lavaram-se num banheiro público ... Um carro da Springfield Traction Company conduziou-os até New Britain e dali à cidade de Hartford. (...) Viu passar a aldeia de sua infância, algumas verstas para além do prado. Um campanário de igreja projetava-se sobre uma colina). 